\title{
A DOGMÁTICA EM DEBATE: \\ FRANZ NEUMANN E AS POSSIBILIDADES EMANCIPATÓRIAS NO MÉTODO JURÍDICO
}

\author{
DOGMATICS IN DEBATE: \\ FRANZ NEUMANN AND THE EMANCIPATORY POSSIBILITIES IN THE LEGAL \\ METHOD
}

FERNANDA VICK ${ }^{1}$

RESUMO: Este artigo busca estabelecer um conjunto de ideias para avançar debates sobre o método jurídico no campo do direito e das políticas públicas, tomando por ponto de partida a lacuna de abordagens sobre a dogmática jurídica. $\mathrm{O}$ artigo apresenta os pressupostos e as regras do jogo sobre o saber e o fazer dos juristas, situando o discurso de crise da dogmática, deflagrado com o advento das políticas públicas, como limite de perspectiva. $\mathrm{O}$ artigo situa o debate da dogmática jurídica no desenvolvimento do direito liberal a partir da crítica de Franz Neumann em "O Império do Direito" (2013; Rodriguez 2009, 2012), cuja perspectiva procedimental propõe não apenas uma tarefa emancipatória para o direito, como também o seu método, como referência para a crítica da dogmática e das doutrinas jurídicas. Como abordagem para avançar estudos internos e interdisciplinares, apresenta a racionalidade do método jurídico para apreensão da realidade social e suas categorias elementares - os sujeitos e as relações jurídicas - demonstrando que o raciocínio jurídico é desenvolvido para a ação atomizada ou individualizada, o que explica dificuldades e dilemas nas tarefas das políticas públicas, sua dimensão institucional e agregada.

Palavras-Chave: Franz Neumann; dogmática jurídica; método jurídico; Estado e políticas públicas; interdisciplinaridade.

ABstract: This article seeks to establish a set of ideas to advance debates on the legal method in the field of law and public policy, taking as a starting point the gap in approaches to legal dogmatics. The article presents the assumptions and rules of the game about "knowing" and "doing" of jurists, placing the discourse of dogmatic crisis, triggered by the advent of public policies, as a limit of perspective. The article places the debate on legal dogmatics in the development of liberal law based on Franz Neumann's critique in "The Empire of Law" (2013; Rodriguez 2009, 2012),

${ }^{1}$ Mestra e Doutoranda no Programa de Pós-Graduação em Direito do Estado da Faculdade de Direito da USP. E-mail: fvick@usp.br. 
whose procedural perspective proposes not only an emancipatory task for law, but also also its method, as a reference for the critique of dogmatics and legal doctrines. As an approach to advance internal and interdisciplinary studies, it presents the rationality of the legal method for the apprehension of social reality and its elementary categories - the subjects and legal relationships - demonstrating that legal reasoning is developed for atomized or individualized action, which explains difficulties and dilemmas in tasks of public policies, their institutional and aggregate dimension.

KeYWORDS: Franz Neumann; legal dogmatics; legal method; State and public policies; interdisciplinarity.

\section{INTRODUÇÃO}

Apesar de os juristas saberem, de forma pragmática, o que podem oferecer à tarefa de formulação e implementação das políticas públicas - combinar normas de todo tipo, competências, processos, padrões de decisões judiciais, doutrinas, etc, para o desempenho de uma tarefa cuja coordenação cabe ao Estado -, a experiência do diálogo interdisciplinar da abordagem Direito e Política Pública (BUCCI, 2013; 2019; 2021; COUTINHO, 2013), tem promovido esforços para descrever objetivamente a sua contribuição, para dentro e para fora da comunidade do Direito. Trata-se, contudo, de empreitada árida em ambas as direções.

Internamente, o campo jurídico enfrenta, há um tempo, diagnósticos de limitação ou inadequação sobre o que se denomina dogmática jurídica - o conjunto organizado de pressupostos de criação e aplicação do direito positivo -, à qual uma parte do campo parece associar um sentido de pensamento sem crítica (CALSAMIGLIA, 1990), de velharia, inadequação, apelo conservador e formalista, um saber em descompasso às exigências da realidade.

Tércio Sampaio Ferraz Junior, na nota de atualização de sua obra (2018) - uma das que estruturam a formação inicial no ensino jurídico há algumas décadas -, comunica este estado de coisas, perguntando-se pela utilidade da dogmática jurídica para os dilemas da sociedade atual. Aponta que o sistema jurídico teria perdido sua diretriz de congruência de normas e fontes, o que resolvia os problemasbásicos da aplicação e interpretação do direito, que a dogmática jurídica estaria padecendo de uma confusão teórica responsável, dentre outras coisas, pelo ativismo judicial e, consequentemente, pela politização das decisões judiciais, o que traz indeterminação ao trabalho dos juízes e ao direito aplicado; além disso, o Estado teria perdido a centralidade do poder normativo.

Ferraz Junior informa, com este diagnóstico, um conjunto de pressupostos que conforma a tradição do saber e do fazer jurídico e explicita a lógica com a qual parte do campo se expressa ao se referir a esta defasagem do seu método: a atividade de aplicação do direito é - ou deve ser - uma tarefa mais ou menos 
objetiva de subsunção, ou seja, a operação elementar da sua técnica consiste em traduzir os conflitos na forma prevista pelos institutos da ciência do direito, adaptando os casos concretos às hipóteses gerais. A complexidade das questões colocadas para o Poder Judiciário e para o positivismo jurídico em função das políticas públicas e dos direitos sociais - cuja provisão é coletiva - trouxe um problema para a técnica do direito - cuja lógica de pensamento é marcadamente individual. A ideia implícita é que dogmática ainda não teria achado desenvolvimento adequado para responder estas questões com mais domínio, o que não é um debate recente: a agenda dos direitos sociais tem dirigido a reflexão sobre o Direito Público e ciência jurídica há mais tempo (KENNEDY, 1983; CLUNE, 2011).

Discursos sobre a inadequação, indeterminação ou falência do direito se multiplicaram no século XX, tendo por inauguração relevante a crítica da "materialização do direito", de Max Weber (RODRIGUEZ, 2009, p. XV-XVI). No tópico destinado à sociologia do direito, Weber criticou a perda do seu caráter formal ante o que considerava como diminuição da precisão do trabalho dos juízes, que passaram a versar sobre sociologia, economia ou ética, em vez de usar conceitos jurídicos em suas sentenças (WEBER, 2004, p. 153). De outro lado, na perspectiva do materialismo histórico, o direito reflete a disputa econômica no interesse da classe dominante e, portanto, se apresenta inevitavelmente como instrumento de dominação (MASCARO, 2013; PACHUKANIS, 2008). Da associação direta e pouco criteriosa entre Estado, direito e as experiências totalitárias do século $\mathrm{XX}$, até críticas teóricas de relevância ao direito social como subversão do direito, como a de Frederick Hayek (MACEDO JUNIOR, 2013), disputando a restrição das tarefas do Estado na economia, parece que não há caminho de debate pelo campo jurídico.

Das ciências que se ocupam das relações sociais e de poder, especialmente a ciência política e a sociologia, há diversas posturas em relação ao objeto e método do direito, que vão de declaradas perspectivas negativas sobre esse saber e sua linguagem, passando pela desconsideração de qualquer relevância até alguns esforços de assimilação e diálogo. Bourdieu, por exemplo, manifestou objetiva desconfiança sobre o poder desmedido dos juristas na criação das manifestações da oficialidade, já que tais profissionais dominam o limite entre regra e transgressão, tendo por parâmetro apenas o próprio senso de justiça ou virtude (BOURDIEU, 2014, p. 92-94). O mesmo desconforto está presente, com outra postura, no esforço de diálogo do cientista político Marcos Nobre sobre a obra de Tércio Sampaio Ferraz Jr, no qual comunicou de forma didática a dificuldade de discernir entre a "técnica jurídica" de aplicação do direito e a "ciência do direito", propriamente (NOBRE, 2011).

Essas duas impressões sobre o trabalho dos juristas, que sintetizam outras tantas observadas, partindo de teóricos de peso, determinaram o primeiro impulso que deu origem às reflexões deste artigo, produzidas no âmbito da disciplina "Estado social em (Re)construção no Brasil", oferecida pela Profa. Dra. Maria Paula 


\section{Dallari Bucci, no PPGD-FDUSP.}

A aridez apontada na abertura deste ensaio diz respeito, portanto, a este cenário de resistência interna e incompreensão externa que determinam, enfim, falta de bases para o diálogo sobre o método da ciência e da técnica do direito, cujo principal efeito é a ausência quase completa de estudos - dentro e fora do direito - sobre esse que pode ser compreendido com um locus de poder fora do radar. Mesmo que haja problemas concretos no ensino jurídico, métodos e raciocínios da ciência do direito soem incompreensíveis ou arcaicos, ou que a prática do direito possa ser, de fato, majoritariamente instrumentalizada para a dominação, isso não muda o fato de que este saber segue determinando os padrões de criação e aplicação do direito e, desta forma, promovendo a direção social em um ou outro rumo.

Como referencial teórico para esta discussão, o segundo impulso que determinou este ensaio, apresentamos as linhas gerais do trabalho do jurista alemão Franz Neumann (1900-1954), ligado à Teoria Crítica da sociedade, que contrariou os diagnósticos e o senso comum sobre a contribuição que a função jurídica teria dado ao nacional-socialismo e, não por acaso, colocou em evidência o papel da ciência do direito e a tarefa dos intérpretes e aplicadores do direito nos conflitos sociais.

Em várias obras, mas especialmente em "O Império do Direito", escrito em 1936, publicada pela primeira vez na década de 1980 (NEUMANN, 2013), o jurista faz a defesa do caráter emancipatório da forma do direito liberal, da sua racionalidade inclusiva e universalizante, de sua técnica baseada em procedimentos e normas materiais. Extrai-se da obra de Neumann, com o auxílio de estudos de referência sobre sua teoria (RODRIGUEZ, 2009; 2012), que a burguesia subverteu império do direito para impedir o avanço das conquistas populares, instaurando o Estado totalitário. Tais estudos já reconheceram, portanto, o vínculo direto entre a dogmática e o Estado de Direito e que o caráter regressivo ou emancipatório desta técnica do poder pode variar com o papel dos seus aplicadores.

Há dois propósitos gerais neste ensaio, parte da organização preliminar de uma reflexão mais ampla que não será esgotada nesta oportunidade.

O primeiro propósito é avançar uma matriz de ideias na qual se possa dialogar acerca dos principais dilemas da dogmática jurídica, propondo uma abordagem sobre o problema: a de que tendo as principais operações do raciocínio jurídico sido desenvolvidas com vocação para o direito privado, a crise do método é, na verdade, apenas um dilema para o direito público, propriamente, para a ação do Estado na provisão de serviços, as políticas públicas. Os modelos de raciocício jurídico foram originalmente desenvolvidos para a reprodução da ação e da interação no nível individual, valendo-se das categorias do sujeito de direito e da relação jurídica. Não são muito disseminados, nesta perspectiva, os debates e modelos jurídicos para assimilar a ação em dimensão agregada ou institucional, apesar de a ciência do direito ter uma figura conceitual adequada a esta reflexão, as instituições jurídicas (REALE, 2000; NEUMANN, 2013), e este pode ser um caminho. 
O segundo propósito, aproveitando este esforço, é comunicar esta dimensão específica do modo do raciocínio elementar com os quais o campo do Direito assimila a realidade, sua dimensão atomizada da ação, a relação jurídica, a técnica com a qual promove a interação. A aposta é que essa elucidação pode ser útil tanto para um exercício de compreensão interno ao campo, sobre o próprio método, e para fazer avançar, também, a comunicação interdisciplinar, especialmente no campo das ciências sociais, que também dialogam nas chaves das interações e relações.

O artigo tem três seções, além desta introdução: na primeira, oferecem-se razões para o estudo dadogmática, seu valor distintivo para o trabalho dos juristas, sua relação direta com os processos de reprodução social; na segunda, apresentam-se as linhas gerais das ideias de Franz Neumann sobre a racionalidade do direito a partir da experiência histórica da formação do direito liberal, seu entendimento sobre a ciência do direito e sua contribuição para a compreensão da racionalidade do direito e para o controle da dogmática pelas pesquisas; na terceira, apresentamos a dogmática suas categorias analíticas elementares da ação individual (sujeito de direito e relações jurídicas) e como isso pode estar na raiz das dificuldades de compreensões agregadas ou institucionais dos problemas públicos.

\section{O saber e o fazer dos juristas: razões para debater a dogmática jurídica}

Alberto Calsamiglia traduz boa parte da percepção social sobre o que fazem os juristas ao citar uma crítica que aponta o uso que o campo faz de uma linguagem incompreensível, apresentando-se como detentor de um saber esotérico ${ }^{2}$ (CALSAMIGLIA, 1990, p. 56). Essas características antiquadas de grupo ou o uso do jargão cifrado incompreensível não deve ofuscar o fato de que o modo com o qual o jurista assimila a realidade e se comunica sobre ela responde a uma técnica de reprodução social.

Os pressupostos desta técnica são ensinados no curto ciclo das disciplinas introdutórias da formação jurídica (Introdução ao estudo do Direito, Teoria Geral do Direito, Filosofia do Direito e Sociologia do Direito), em que o Direito é apresentado em seus fundamentos, sua relação com outras disciplinas, a justificação filosófica, as disputas na Teoria Geral do Direito, as normas e o ordenamento jurídico, os princípios, a interpretação e a integração desse sistema unitário, com seus códigos e lógicas elementares de linguagem (categorias e instituições) (REALE, 2000). Após este estágio, os cursos de graduação em Direito mergulham nas doutrinas especializadas das disciplinas (Direito Civil, Penal,

\footnotetext{
2 Calsamiglia reconhece, em alguma medida, o problema da linguagem do direito, mas refuta a crítica do esoterismo, observando que ela se aplica, de modo geral, a toda ciência porque, em relação ao senso comum, o saber científico é naturalmente objeto de uma comunidade restrita, na medida em que apenas reconhece a comunicação sobre um objeto com base em pressupostos rigorosos, compartilhados exclusivamente pelos seus estudiosos.
} 
Tributário, Administrativo, etc), de modo que o método e os seus raciocínios vão sendo naturalizados sem que se volte a sua reflexão com maior elaboração e maturidade.

Esta seção propõe, portanto, algumas considerações preliminares no esforço de comunicar o que se está deixando passar a respeito desse tema, na forma de assertivas sobre a natureza, lógica de operação e observações sociológicas referentes à dogmática jurídica, o que certamente merece debates aprofundados e pesquisas empíricas, mas que servem à reflexão deste artigo:

a. Um ordenamento de direito positivo é um complexo unitário de disposições sobre o poder, e a dogmática jurídica é a sua linguagem. Isso quer dizer que todas as suas disposições ordenadas dizem respeito a tramas de relações sociais às quais foram dadas garantias específicas, pela coerção. Essa totalidade de tratamento não significa que as normas jurídicas regulem tudo, mas essa ausência de intervenção é política e está compreendida no regime de garantias jurídicas, protegendo o poder privado de interferências. A forma ordinária como tudo isso se conecta está tratada pelas categorias, instituições e sistemas de forma ampla na ciência do direito.

b. A dogmática jurídica - que são os consensos de interpretação e aplicação da ciência do direito aos casos - é, portanto, uma correia de transmissão direta entre um campo do saber (as teorias, o ensino e a pesquisa) e os mais variados processos decisórios pelos quais a sociedade se reproduz (negociais, administrativos, políticos, judiciais); essa é sua vocação para a decidibilidade, (FERRAZ JR, 2018), ainda que nem tudo em direito venha a se tornar uma questão a ser decidida em processo judicial. As relações sociais incorporadas pelos modelos jurídicos reproduzem-se apenas pela iminência de uma decisão que será imposta pela coerção.

c. Essa transmissão direta ou não mediada diz respeito ao fato de que este saber que se convola no fazer (a decisão, o negócio, o ato que dá impulso à certa dinâmica social) em distintas esferas de poder transita exclusivamente nessa comunidade autorreferenciada de juristas, um conjunto de autoridades políticas, administrativas, judiciais, advogados e acadêmicos. A linguagem jurídica engendra a ação do Estado, saber que, portanto, será constantemente validado pela autoridade pública que decide, ou sua assessoria que lhe fornece razões técnicas para tanto, ou o juiz que lhe confirma o sentido da norma e, portanto, endossa certo entendimento sobre a técnica do poder jurídico ou coerção. A ciência do direito e a dogmática são o conteúdo do ensino, a razão 
de decidir, o fundamento da coerção com a qual - num ciclo interminável - se endossa o que se ensina ser o Direito.

d. Desse modo, a dogmática jurídica acaba se revelando verdadeira instância de mediação do processo de aplicação do direito, ou seja, do exercício do poder, o que faz dela elemento essencial do próprio Estado de Direito (RODRIGUEZ, 2009; 2012), definindo os contornos do ordenamento jurídico e, indiretamente, de boa parte das instituições sociais. O debate da dogmática é o único caminho para se submeter a escrutínio um pouco mais amplo o processo de aplicação do direito para além dos tribunais: "se menos desenvolvida a dogmática, mais imprecisa é a decisão dos tribunais" (CALSAMIGLIA, 1990, p. 79).

e. Todos estes atributos da dogmática jurídica fazem do ensino jurídico e da comunidade de aplicadores e cientistas do direito um campo de estudos mais amplo sobre racionalidade e operação do Direito, além dos juízes e da administração da justiça que têm centralidade na sociologia do direito (Treves, 2004, p. 260). O repertório do direito está determinado não apenas no que decidem os juízes, mas nos sentidos que diversos aplicadores conferem às normas e teorias na burocracia, na execução das políticas, na constante comunicação que as esferas de aplicação do direito têm com a comunidade do ensino e da pesquisa, além do mercado das publicações jurídicas especializadas. O único controle que existe é interno. As minúcias desse saber decisório apenas eventualmente chegam ao debate judicial e seus sentidos vão se confirmando com relativa autonomia dessa comunidade.

f. Existe, portanto, um monopólio de fato sobre como o direito é e como o direito pode ser, poder não regulado diretamente pela lei, mas, sim, pelo que os juristas elaboram sobre ela. Ou seja, para informar os novos parâmetros de aplicação do direito, qualquer tipo de conhecimento precisa entrar na linguagem operacional da comunidade de juristas.

A associação da dogmática jurídica a um saber não crítico e não submetido à racionalidade - discurso que tem se tornado comum no próprio campo do direito - chega a ser uma crítica não apenas descuidada, mas alheia ao próprio objeto e método do Direito: enquanto ciência da norma positivada por uma autoridade política, dirigidaa determinar racionalidade ao ordenamento jurídico, a dogmática lida com pressupostos inescusáveis, as normas, o modo de identificá-las, de interpretá-las e de usá-las na regulação das dinâmicas sociais.

O dogmatismo é a posição que existe na ciência do direito quanto aos pressupostos e às regras do jogo o consenso sobre os sentidos da aplicação que é compartilhado pelos juristas e, neste sentido, a dogmática é a mediação entre 
a ciência e política (CALSAMIGLIA, 1990, p. 76 e 79). Como código elementar da linguagem operacional do poder jurídico - o conteúdo da formação e do ensino e da pesquisa -, determina grande parte do exercício do poder político em sociedades organizadas com a centralidade do Estado. Ignorar como ela é construída e disputada é abrir mão de compreender, em lentes analíticas, como a técnica jurídica opera nas relações de poder, como conforma instituições e quem opera essas coisas, induzindo a reprodução social em um ou outro sentido. É ao que Norberto Bobbio se referiu quando teorizou sobre a função promocional do direito, no sentido de que, a partir das sanções jurídicas, o direito pode realizar propriamente a direção social (BÓBBIO, 2007).

A vocação da dogmática jurídica para a intervenção sobre conflitos por órgãos com competência para arbitrar a solução do caso - a decidibilidade - é apenas o ato final ou a garantia do projeto de regulação social que a ciência do direito engendra, compreendo uma tecnologia de projeção e organização das interações entre as pessoas e do funcionamento das instituições públicas e privadas com o propósito de controlar e coordenar comportamentos, estabelecendo estímulos (punitivos ou não) e construindo algum grau de previsibilidade social.

A decidibilidade, como razão da ciência do direito, diz respeito ao fato de que toda a construção teórica que está nos manuais de direito e nas formas elementares do raciocínio jurídico, aofim e ao cabo, conformará o parâmetro da decisão sobre conflitos eventualmente não absorvidos neste esquema de reprodução social, a ser utilizado pelo julgador último de uma lide processual submetida à apreciação de órgãos de Estado.

Na obra em que debate o trabalho de Franz Neumann, objeto da seção seguinte, Rodriguez destaca que o teórico equipara a tarefa de julgar e de administrar como atos de aplicação do direito, distintos apenas pelo grau de indeterminação:

\footnotetext{
"Administrar e julgar são atos de aplicação de normas jurídicas. Serão mais ou menos indeterminados conforme o desenho das normas substantivas e adjetivas.

(...)

Juízes e administradores, no limite, estão sujeitos a normas jurídicas, afinal, num Estado de Direito, todo ato de poder deve ser referido a uma norma geral, substantiva ou adjetiva. A diferença é que as normas que regulam a atividade dos juízes tendem a atribuir-lhes a competência para julgar conforme o texto de uma lei. Os administradores, de outro lado, têm o poder de mediar interesses sem se referir a textos de lei que estabeleçam hipóteses de comportamento nas quais estes conflitos devam encaixar-se" (RODRIGUEZ, 2009, p. 113)
}

Assim, o uso que os administradores fazem da técnica jurídica, portanto, são 
escolhas mais amplas sobre as formas de comportamento com as quais se poderá induzir a direção dos conflitos sociais e colocar o aparato do poder para torná-la exigível. O judiciário apenas eventualmente se informará dessas escolhas.

Neste artigo, usa-se o termo "dogmática jurídica" segundo a perspectiva pragmáticaadotada por Calsamiglia: o saber (ciência jurídica) e o fazer (o direito aplicado) dos juristas, sem entrar, neste momento, na distinção entre o que se chama ciência do direito e a técnica de aplicação: dogmática jurídica transita fluidamente entre funções descritivas (o que é) e prescritivas (o que deve ser) do fenômeno jurídico ${ }^{3}$. José Rodrigo Rodriguez produz um debate renovado sobre a dogmática jurídica no Brasil (RODRIGUEZ, 2009; 2012), tentando comunicar a racionalidade do direito e da tarefa dos aplicadores e pesquisadores do campo:

\begin{abstract}
“A dogmática jurídica é um conjunto de raciocínios destinado a organizar sistematicamente, com a utilização de conceitos, institutos e princípios jurídicos, as leis eos casos julgados em um determinado ordenamento jurídico, nacional ou transnacional, tendo em vista a solução de casos concretos por meio de organismos de natureza jurisdicional. Pode haver pensamento dogmático sobre o direito brasileiro (e seus assuntos), sobre o direito internacional, sobre o direito do comércio internacional, sobre o direito da internet, etc., desde que esteja ligado a determinados centros de produção normativa e a organismos jurisdicionais encarregados de decidir conflitos, não necessariamente um Poder Judiciário organizado em bases nacionais." (RODRIGUEZ, 2012, p. 22)
\end{abstract}

$\mathrm{Na}$ base de todos os campos doutrinários da dogmática, existem chaves analíticas elementares comuns, que são as formas como os aplicadores do direito apreendem a realidade e inscrevem as interações e as dinâmicas sociais a fim de aplicar a norma aos casos. São as relações jurídicas que se estabelecem entre sujeitos de direito no interesse do direito de um deles, obrigando o outro a uma prestação, sujeção ou faculdades. Esse é o método da interação social juridicamente garantida.

\title{
3. NEUMANN E A RACIONALIDADE EMANCIPATÓRIA DO DIREITO
}

Resgatar o trabalho de Franz Neumann e suas ideias sobre o fenômeno do direito liberal ilumina caminhos para o esforço de comunicação sobre o que fazem

\footnotetext{
${ }^{3}$ Calsamiglia faz referência à exaustiva disputa teórica sobre o caráter científico da ciência jurídica, sua confusão com o próprio objeto, ambigüidade do termo "Direito" (como norma posta, ordenamento ou ciência), o que por si dificulta a constituição de uma ciência jurídica absolutamente diferenciada do próprio objeto aplicado. Questiona sobre a utilidade deste debate inclusive pelo fato de que acabam dirigidos a julgamentos de valor sobre o saber
} 
os juristas e como o fazem. Destacam-se dois temas da obra de Franz Neumann pertinentes para a reflexão sobre a dogmática deste pequeno ensaio: primeiro, sua compreensão sobre a ciência do direito - tanto as normas quanto a realidade social - com impacto para uma visão tradicional sobre a aplicação e a construção do saber jurídico; segundo, sua compreensão sobre os direitos fundamentais na experiência histórica da formação do direito liberal, derivando os direitos sociais dos direitos econômicos (NEUMANN, 2013), que tem por elemento central o direito de propriedade.

Contra o diagnóstico de instrumentalização exclusivamente negativa que a tradição marxista confere à forma direito, Neumann apresenta a racionalidade do direito liberal como intrinsecamente inclusiva e universalizante, de onde extrai seu potencial emancipatório, linguagem do poder com a vocação de absorver as demandas sociais e incluir grupos desfavorecidos pela conformação jurídica do conflito político. Sobre a compreensão de Neuman acerca da origem desta forma de sociabilidade, Rodriguez sintetiza que o império do direito, enquanto legitimação da forma política do Estado, nasceu do esforço teórico e político para afirmar a burguesia como classe excluída da ação política:

"Ao defender que o Estado deve realizar a vontade da sociedade, a burguesia pôde figurar a si mesma como portadora dos interesses universais, forçando sua entrada na condução de suas políticas, ou seja, na definição do que seja interesse público. O processo real de construção dos Estados de Direito resultou na destruição do antigo regime. Suas estruturas não suportavam a participação de outras classes além da aristocracia e clero na formação da vontade do soberano (RODRIGUEZ, 2009, p. 70).

O caráter emancipatório e revolucionário da forma direito está no padrão de inclusão política que ele inaugura a partir de uma linguagem formal de normas procedimentais e materiais, o que se tornou estruturante da racionalidade jurídica e permitiu ao proletariado mimetizar o mesmo movimento de luta, a ponto de obrigar a burguesia, posteriormente, a negar sua criatura:

A edificação do império do direito e suas instituições fundamentais, especialmente o governo das leis por meio de normas gerais, se dá em função do interesse da burguesia em trocas econômicas calculáveis e previsíveis. No entanto, ao viabilizar ao funcionamento do mercado com a construção de um direito formal, a burguesia fez mais do que gostaria. Instituiu uma forma de regular, a norma geral, que permitiria, mais tarde, o nascimento da tendência capaz de destruir o sistema capitalista. As normas jurídicas são, por assim dizer, facas de dois gumes, pois permitem 
conformar e regular as trocas em função dos interesses de seus participantes, mas também de interesses extramercado." (RODRIGUEZ, 2009, pp. 70-71, grifos nossos)."

Para Neumann, o "direito (law) é uma realidade que tem como função servir à ideia do direito (Rechtsidee)" (NEUMANN, 2013, p. 49) e, neste sentido, só existe no movimento em direção a esta ideia, que implica tanto uma demanda por justiça quanto por satisfação de necessidades sociais e estatais (RODRIGUEZ, 2009, p. 121). Tal como historicamente concebido, o direito não é instrumental às lutas políticas, mas constitutiva da própria sociabilidade: "O pressuposto é que o direito é um dos lugares em que a sociedade constrói a si mesma, moldando suas instituições e suas práticas" (RODRIGUEZ, 2009, p. 84).

Auxiliando na compreensão da obra de Neumann, Rodriguez afirma que a forma direito é um método de estabelecimento de contradição de interesses, sem promessas de solução a priori, sempre moldável aos novos conflitos e demandas e sempre capaz de forjar novas instituições, movido pela racionalidade geral de atender necessidades de grupos que demonstram a exclusão no âmbito de sua abrangência. Foi assim que a burguesia justificou a sua criação na luta contra o Antigo Regime e assim, também, que teve seus privilégios de classe questionados pelo proletariado, o que demonstra autonomia da forma direito em relação ao sujeito histórico original.

Esta racionalidade da regulação inclusiva das novas demandas se viabiliza por sua lógica procedimental, combinando elementos substantivos (a afirmação de conteúdos mínimos, como igualdade formal ou legalidade) e adjetivos ou procedimentais, como que todos podem inscrever-se na disputa política. Neste sentido, "emancipar-se significa conformar e garantir institucionalmente a possibilidade de expressar insatisfação" (RODRIGUEZ, 2009, p. 77).

É neste ponto que Neumann traz outra contribuição relevante para a compreensão da racionalidade do direito a partir de sua conformação na fase monopolista do capitalismo, em que o direito se torna central para a reprodução do sistema: erigida a propriedade privada como direito, introduzira-se "o elemento material na forma, ocupada originalmente apenas com o valor da igualdade formal entre os cidadãos" (RODRIGUEZ, 2009, p. 81).

A forma direito se perfaz com o mínimo representado pelas liberdades individuais e políticas, que criam as condições institucionais para disputa pela conformação do Estado. A tutela jurídica da propriedade, neste caso, é elemento de direito material que, refletindo a situação histórica subjacente, acabava tutelando, de forma prática, o acúmulo da classe burguesa. Contudo, em Neumann, a propriedade não integrava a tradicional categoria dos direitos individuais ou pessoais, conforme classificação corrente ${ }^{4}$, mas a categoria dos direitos econômicos,

\footnotetext{
${ }^{4}$ José Afonso da Silva reconhece essa classificação ao ressalvar que não pode mais ser assim interpretada: ainda que o direito à propriedade privada conste no rol dos direitos individuais na
} 
o que colocou a situação de fato da burguesia em risco, quando o proletariado buscou transformar o conteúdo material do direito de propriedade ao ocupar o Parlamento, denunciando a desigualdade de classe:

\begin{abstract}
“Além dessas distinções de acordo com categorias do direito constitucional positivo, distinguimos as liberdades fundamentais de acordo com sua matéria. Desse ponto de vista temos de notar a existência dos chamados direitos individuais ou pessoais de liberdade. Estes constituem os direitos fundamentais do indivíduo isolado, tais como a proteção contra detenção ilegal, direito à moradia e inviolabilidade da correspondência, garantia de liberdade de religião e de consciência.

Como uma segunda categoria, sugem os chamados direitos políticos de liberdade. (...)

Uma terceira categoria é apresentada pelos direitos de liberdade econômica. O direito econômico central é a propriedade. (...). As liberdades suplementares do direito de propriedade são liberdades de contrato, de comércio e de usufruto." (NEUMANN, 2013, pp. 85-86)
\end{abstract}

Essa interpretação coloca em outro patamar a discussão sobre a legitimidade dos direitos sociais. Mostra que a tutela dos direitos de propriedade é uma importante intervenção distributiva na ordem econômica, em privilégio a uma classe, e que os direitos sociais - oriundos que são dos direitos econômicos nascem, portanto, da legítima disputa pela redistribuição do excedente social (RODRIGUEZ, 2009, p. 89), como valor da ordem jurídica. É assim que se extrai, da obra de Neumann, que a forma direito deixa de ser alienante ou instrumento de dominação, o que explica porque a burguesia a abandonou como justificação do Estado, surpreendida na contradição que tentava ocultar sob a forma de princípios universais - a desigualdade de classe e seus privilégios de propriedade como direito. E é, assim, que passa a apelar para formas irracionalistas de legitimidade do poder, como a ideia de nação (RODRIGUEZ, p. 83).

Grande parte da preocupação de Neumann ao teorizar sobre o império do direito foi, portanto, esse espaço de indeterminação para a aplicação das normas e como cercar esse processo com critérios, reflexões que ele desenvolveu afirmando a racionalidade da forma direito, procurando evidenciar que tal racionalidade foi paulatinamente suprimida até chegar ao regime totalitário do nacional-socialismo, uma experiência de não-Estado e não-direito, apesar de revestido de algumas formas, como ele registra em conhecida obra Behemoth (NEUMANN, 2005, p. 11).

Os primeiros movimentos de supressão do Estado de Direito desenvolveram-se

Constituição de 1988, a positivação da sua função social modificou esse caráter (SILVA, 2007, pp. 270-271). 
já nos primeiros anos da Constituição de Weimar, pela interpretação do direito exercida nos tribunais: julgando os conflitos e as leis decorrentes dos direitos sociais inscritos naquele texto, os juízes alemães, protegidos pela aura de neutralidade da interpretação jurídica, bloquearam o desenvolvimento concreto das conquistas dos trabalhadores:

\begin{abstract}
"As regras do jogo que a burguesia criou para o funcionamento dos Estados de Direito incluíam a garantia da igualdade perante a lei, bem como a liberdade e a segurança individual para todos os indivíduos. Além disso, havia a liberdade de associação e o direito de voto. Todas estas instituições serviram para que o proletariado tomasse parte do sistema político e adentrasse o parlamento para fazer exigências na forma de reivindicação de direitos. Assim que a influência da burguesia no parlamento diminui, o mesmo acontece com seu compromisso com esta forma de representação. Durante Weimar, o aumento do controle judicial sobre o Parlamento pode ser interpretado como uma reação ao avanço das leis sobre o direito de propriedade privada dos meios de produção." (RODRIGUEZ, 2009, p. 50).
\end{abstract}

Neste aspecto, chama a atenção, particularmente, que Neumann se vale de uma categoria da dogmática para explicar a função que o direito de propriedade poderia ter para sustentar a tutela da propriedade burguesa apesar das disposições constitucionais trazidas em Weimar: a instituição jurídica.

A instituição jurídica é uma concentração da regulação em torno de uma instituição social, cuja produção e reprodução se visa preservar e assegurar: "Todas as instituições que servem à produção e reprodução de relações humanas e que pretendem ser duradouras são, portanto, instituições jurídicas" (NEUMANN, 2013, p. 90). Como explica Reale, as relações sociais que reúnem mais de um elemento relevante para compor sua unidade lógica de funcionamento - a família, a propriedade, o matrinônio - podem conformam instituições jurídicas, reunindo um complexo normativo em torno desses elementos (REALE, 2000, p. 191).

A propriedade dos meios de produção, como instituição, foi organizada em torno de um conjunto de especificações jurídicas para a posse, administração, extração do lucro e poder de comando, tendo, portanto, importantes barreiras para se implementar enquanto direito de outra natureza, consolidando exclusivamente os interesses de uma classe - a proprietária - apartir da construção doutrinária.

É essa indeterminação do sentido do direito, circunscrita no monopólio da interpretação, que Neumann ajuda a compreender. Em defesa da forma direito, Neumann debateu com Kelsen e com Max Weber, criticando tanto o esquema supostamente objetivo de aplicação do direito pela subsunção dos casos às normas gerais (teoria pura do direito) quanto o fatalismo weberiano acerca da perda da 
racionalidade do direito com a presença de juízos de valor no processo de aplicação. Uma parte da resposta de Neumann a este problema da indeterminação passou por reformular a própria noção do objeto da ciência do direito, implicando outra compreensão sobre a análise da aplicação do direito e das pesquisas empíricas que devem ser empreendidas pelo comunidade de juristas como parte do próprio controle que deve ser exercido sobre a dogmática.

Diferente da perspectiva da Teoria Pura do Direito, Neumann considera como objeto da ciência do direito tanto as normas quanto a realidade social à qual ela se dirige:

Enquanto uma ciência das normas, esta tem como questão o significado das normas jurídicas. Enquanto uma ciência da realidade, ela investiga as relações entre normas jurídicas, a subestrutura (Substrat) social, o comportamento social de sujeitos jurídicos e dos administradores do direito. (...)

A ciência das normas tem como questão a ordem jurídica, considerada uma estrutura mental autônoma, oposta a realidade. (...)

A ciência jurídica não concerne apenas às normas jurídicas, mas também à subestrutura social do sistema jurídico. Entendemos pelo termo "subestrutura social" a realidade social depois da subtração do próprio direito. A realidade social é o trabalho dos homens. A norma jurídica ordena a realidade social, isto é, ..., sob certas condições, a ordenação das relações sociais adota um caráter jurídico. O direito é a ordem específica da subestrutura social (NEUMANN, 2013, pp. 49-54)

Rodriguez aponta para o momento sociológico da ciência do direito, referindose a este aspecto do objeto com a reformulação que lhe deu Neumann, destacando que cabe aos juristas não apenas a tarefa técnica de descrever e sistematizar a dogmática, mas de estudar os fenômenos da aplicação e seus agentes, numa compreensão que torna problemática separação entre filosofia do direito, sociologia do direito e dogmática (RODRIGUEZ, 2009, pp. 117-118).

Estes recortes muito sintéticos sobre a imensa contribuição de Franz Neumann permitem ressaltar o papel que as doutrinas jurídicas desempenham no controle da aplicação do direito e em sua própria conformação, determinando suas possibilidades emancipatórias ou sua tendência regressiva.

\section{DOGMÁTICA JURÍDICA E SUAS CATEGORIAS ELEMENTARES: UMA PROPOSTA DE COMPREENSÃO DO PROBLEMA}

A dogmática jurídica, pensada como modelo de regulação formal para a reprodução da circulação - a operação elementar do mercado -, foi construída 
sobre categorias de análise que descrevem as dinâmicas sociais em perspectiva atomizada, mimetizando as relações de troca econômica (CLUNE, 1993; RODRIGUEZ, 2009, p. 70-71; EDELMAN, 1973) ${ }^{5}$. A matriz original de concepção e esquemas de pensamento da dogmática jurídica é o direito privado: a relação jurídica, como categoria fundamental da ciência do direito, foi desenvolvida por Friedrich Carl von Savigny, juntamente com tantas outras elaborações da teoria geral do direito e do direito civil (REALE, 2000).

Aliás, um dos importantes paradigmas de linguagem extraído desse desenvolvimento histórico do direito é o que inscreve a ação do Estado para regular a sociedade como "intervenção", sempre extraordinária ou subsidiária, a demandar justificativas e promover disputas políticas, como se uma certa conformação da tutela jurídica da propriedade e dos contratos privados não fosse relevante manifestação de intervenção pública capazes de determinar desigualdades ou justiça redistributiva, como mostram as reflexões de Neumann na sessão anterior.

A par dessa conformação, observe-se que o campo do direito privado tradicional não experimenta dilemas consideráveis sobre a atualidade ou adequação do método jurídico. Ao contrário, a dogmática continua a manifestar operacionalidade sem maiores perturbações: juristas que lidam com contratos imobiliários, direito de família, transações comerciais, processos licitatórios, etc, conflitos ou problemas jurídicos que, em regra, estão bem descritos em leis, modelos doutrinários e contratos, não estão envolvidos neste dilema do descompasso da dogmática jurídica com a realidade, ao menos não a ponto de produzirem o descrédito do seu método.

Em termos analíticos, as construções do pensamento jurídico se valem da categoria elementar do sujeito de direito e inscrevem a ação na chave de relações jurídicas, visando imputar responsabilidade jurídica e exigir cumprimento de conduta por meio da força. Esta descrição da ação em perspectiva jurídica estrutura todos os campos doutrinários da dogmática (autor e réu, contribuintefazenda; devedor-credor; contratante-contratado), pois são os conceitos básicos com os quais os operadores do direito apreendem as dinâmicas da vida social pelos comandos jurídicos, para o que se dirige todaa reflexão teórica do direito aplicado.

A noção de relação jurídica é analisada no âmbito do sentido processual das políticas públicas por Bucci que, citando Carnelutti, explica as chaves de análise do repertório do direito para as interações entre sujeitos:

“Relação jurídica é a relação social regulada pelo direito [...] [que se

\footnotetext{
${ }^{5}$ Neste sentido, a perspectiva marxista descreve o fenômeno com precisão. A contribuição do direito para a apropriação do produto do trabalho foi inscrevê-lo como objeto de troca, passível de circulação a partir da figura do sujeito de direito, o indivíduo destacado de sua energia de trabalho, que a negocia livremente.
} 
aclara] desde que a consideremos com um conflito de interesses e se considere o efeito de sua regulamentação como atribuição aos interessados respectivamente de um poder e de um dever.

Os três pares - obrigação-faculdade, direito subjetivo-sujeição, potestas-sujeição - constituem espécie do genus relação jurídica. Ora, o que a distinção entre estática e dinâmica e consequentemente entre situação e fato jurídico tem de mais valioso é fornecer-nos a chave de convertibilidade de qualquer desses pares entre si, porque é na sua conversão contínua, por meio do fato jurídico, que se reolve o movimento do direito" (BUCCI, 2013, p. 116).

Em outras palavras, o direito descreve todas as dinâmicas em relações jurídicas, posicionando sujeitos de direito em correspondência ativa e passiva, em diversos pares conhecidos por estrutura de posições jurídicas: "Posição jurídica é aqui entendida como termo de relação jurídica, seja ela ativa (direitos e poderes) ou passiva (deveres ou sujeições)" (FREIRE, 2017).

Desta forma, quando o direito objetiva regular alguma dinâmica, sua operação elementar é inscrever os sujeitos (indivíduos e organizações) em relações, colocando-os em posições correspondentes recíprocas, às quais se imputam condutas ou efeitos, induzindo a ação por estímulos, com possibilidade do uso da coerção, em alguma medida. Ainda que vocacionada a coordenar comportamento sem interferir sobre ele diretamente, como ocorre no mundo dos contratos e negócios jurídicos privados em geral, é na possibilidade latente de exigir comportamento (impondo consequências, sanções, confiscando bens, imputando multas, obrigações, atribuindo direitos) que reside a força dos modelos jurídicos de ação e sua capacidade de induzir a reprodução social.

Esse modelo de operação, pensado na base do direito privado, é, na verdade, o modelo de análise de todo o direito, inclusive naquele que se desenvolveu o direito público. O repertório da dogmática para a ação do Estado, respeitando a conformação histórica de origem do direito liberal, traz muitos pressupostos do esquema de pensamento que conforma as ações dos agentes privados, o que tem potencial para explicar boa parte dos problemas atualmente inscritos no discurso como crise da dogmática jurídica. Esta constatação se confirma, por exemplo, no advento da personalidade jurídica do Estado - que o faz sujeito de direito formal e o insere em modelos de relações jurídicas da mesma forma que indivíduos; também se apresenta no mimetismo que existe entre as categorias do Direito Administrativo com as categorias do Direito Civil (ato administrativo, validade, a dimensão atomizada do processo).

Se esse padrão de operações é eficiente para ordenar e tornar previsíveis comportamentos atomizados, precisa de elementos de agregação para ser útil à organização de realidades sociais no nível institucional. É nas necessidades no Direito Público, portanto, que surgem os principais dilemas, que podem ser 
descritos no registro da ambiguidade: por um lado, a sensação de intangibilidade da política pelo direito, ao menos do que se apresenta como excessivamente irracional; por outro, nas polêmicas correntes sobre a judicialização da política e da crítica do ativismo judicial.

De certa maneira, os processos e procedimentos representam um nível de organização neste aspecto, mas no campo da gestão e da política seu curso sofre intervenções menos reguladas pelo direito, tendo limitações para organizar elementos com a garantia jurídica.

Neste sentido, diferente do que sugere o diagnóstico de crise, propõe-se investigar com mais rigor as lacunas da dogmática jurídica para a ação do Estado nas políticas públicas para propor caminhos que podem ser trilhados visando desenvolvê-la, mantido o compromisso como método jurídico em que está inscrita. A partir das lições de Neumann sobre a racionalidade do direito, pode-se dizer que o cenário de disputa política sobre a ação do Estado nas políticas públicas coloca como valor a necessidade de avançar o repertório da dogmática para a consolidação e mantutenção das conquistas institucionais no campo dos direitos sociais.

Há importantes avanços teóricos sobre a perspectiva jurídica da ação do Estado produzidos pela abordagem Direito e Políticas Públicas (BUCCI, 2019; 2013; COUTINHO, 2013), que buscam compatibilizar o repertório dos campos disciplinares do direito aos problemas que as políticas públicas enfrentam, em especial uma compreensão da ação do Estado em perspectiva institucional ou agregada, para o que pode contribuir a perspectiva de modelos jurídicos (BUCCI, 2016).

Um desses avanços foi a concepção da ação governamental em níveis macro, meso e microinstitucional, modelo de análise que pode abrir espaço para construções dogmáticas no sentido imprimir mais racionalidade às disputas políticas, a partir da técnica jurídica. Com ele pode ser combinada uma análise criteriosa do conceito jurídico de instituição jurídica, como núcleo que congrega várias regulações para proteger a unidade de realidades sociais complexas que apenas fazem sentido com a preservação de diversos elementos (NEUMANN, 2013; REALE, 2000, p. 190). É algo para se desenvolver, se esta base de diálogos puder ser útil para tanto.

\section{REFERÊNCIAS BIBLIOGRÁFICAS}

BOBBIO, Norberto. Da estrutura à função: novos estudos de teoria do direito. 1.ed. Tradução de Daniela Beecaccia VeBiani. Buueri, SP: Manole. 2007.

BUCCI, M.P.D. Fundamentos para uma teoria jurídica das políticas públicas. 1.ed. Saraiva, 2013.

(2016). Quadro de referência de uma política pública: primeiras linhas de uma visão jurídico-institucional. Revista eletrônica. Direito do Estado, ano 2016, no 122. 
Disponível em http://www.direitodoestado.com.br/colunistas/maria-paula-dallaribucci/quadro-de-referencia-de-uma-politica-publica-primeiras-linhas-de-uma-visaojuridico-institucional.

(2019). Método e aplicações da abordagem direito e políticas públicas (dpp). Revista Estudos Institucionais, v. 5, n. 3, p. 791-832, set./dez. 2019.

CALSAMIGLIA. Alberto (1990). Introdución a la Ciencia Jurídica. 3a ed. Barcelona: Editorial Ariel S.A.

CLUNE, William H. Legal Disintegration and a Theory of the State. German Law Journal, v. 12, n. 1, p. 186-205, 2011.

(1993). Law and Public Policy: Map of an Area. 2 Southern. California Interdisciplinary Law Journal 1.

EDELMAN, Bernard. $O$ direito captado pela fotografia: elementos para uma teoria marxista do direito. Tradução: Soveral Martins e Pires de Carvalho. Coimbra: Centelha, 1976.

FERRAZ Jr., Tércio Sampaio. Introdução ao estudo do direito. Técnica, decisão, dominação. $10^{a}$ edição. Rio de Janeiro: Gen/Atlas, 2018. Nota a um leitor intrigado, pp. .

FREIRE, André Luiz. A teoria das posições jurídicas de Wesley Newcomb Hohfeld. Enciclopédia jurídica da PUC. Tomo Teoria Geral e Filosofia do Direito, Edição 1, Abril de2017. Disponível em: https:/enciclopediajuridica.pucsp.br/verbete/1/edicao-1/a-teoriadas- posicoes-juridicas-de-wesley-newcomb-hohfeld. Acesso em: 01 jul 2021.

KENNEDY, Duncan. The Political Significance of the Structure of the Law School Curriculum, Setton Hall Law Review, vol. 14-1, 1983, p. 1-16.

MACEDO Jr, Ronaldo Porto. (2013). O conceito de direito social e racionalidades em conflito: Ewald contra Hayek. In Ensaios de Teoria do Direito. São Paulo: Saraiva, cap 2, pp. 57-107.

MASCARO, Alysson L. Introdução ao estudo do direito. 4.ed. São Paulo: Gen/Atlas, 2013.

NEUMANN, Franz L. (2013). O império do direito. Teoria política e sistema jurídico na sociedade moderna. Trad. Rúrion Soares Melo. São Paulo: Quartier Latin, 2013.

(2005). Behemoth: pensamiento y acción en el nacional-socialismo. Traducción de Vicente Herrero y Javier Márquez. México: Fondo de Cultura Económica, 1943.

RODRIGUEZ, José Rodrigo. Dogmática é conflito: a racionalidade jurídica entre sistema e problema. In dogmática é conflito: uma visão crítica da racionalidade jurídica. José Rodrigo Rodriguez, Flávia Puschell e Marta Machado. São Paulo: Saraiva, 2012. p. 21- 
32.

Fuga do direito. Um estudo sobre o direito contemporâneo a partir de FranzNeumann. 1.ed. Saraiva: São Paulo, 2009.

SILVA, José Afonso da. Direito constitucional positivo. 30.ed. São Paulo: Malheiros, 2007.

TREVES, Renato. Sociologia do Direito. Origens, pesquisas e problemas. 3.ed. Tradução de Marcelo Branchini. Barueri: Manole, 2004.

WEBER, Max. Economia e sociedade: fundamentos da sociologia compreensiva. Vol. 2. Tradução de Regis Barbosa e Karen Elsabe Barbosa. São Paulo: UNB editora, 2004. 